\title{
Adsorption of Vapor Phase Mercury on Various Carbons
}

\author{
Jinjing Luo ${ }^{1}$, A. M. Hein ${ }^{2}$, and J.Y. Hwang ${ }^{3 *}$, \\ ${ }^{1}$ Dept. of Civil \& Environmental Engineering, ${ }^{2}$ Institutue of Materials Processing, and \\ ${ }^{3}$ Dept. of Materials Science \& Engineering, \\ Michigan Technological University, Houghton, MI 49931, U. S. A.
}

\begin{abstract}
Unburned carbon was found to be a component of fly ash resulting from incomplete combustion in a pulverized-coal based power plant. Previous investigations found that unburned carbon separated from fly ash exhibited good mercury adsorption property. It would offer an opportunity to substitute activated carbon with low cost unburned carbon for mercury adsorption from power plant emission gases. This study provides a comparison of mercury adsorption by carbon from various sources, including activated carbon and unburned carbon from two different power plants. The experiments were conducted under various temperatures and mercury concentrations to determine whether good mercury adsorption properties can be obtained from various carbon sources. This study revealed that mercury adsorption depended on the carbon sources and conditions. Activated carbon (F400) demonstrated the best mercury absorbability among the three tested carbons, followed by AEP unburned carbon. Pepco unburned carbon showed very little mercury absorbability. Increasing the temperature generally resulted in the decrease of mercury adsorption. Adsorption rate could be effectively increased with increasing gaseous $\mathrm{Hg}$ concentration. Desorption treatment before adsorption test could improve unburned carbon's adsorption capacity, especially for Pepco carbon.
\end{abstract}

KEY WORDS: Mercury, Adsorption, Activated Carbon, Unburned Carbon

\section{INTRODUCTION}

In 1995, around 5500 tons of mercury was emitted globally into the atmosphere ${ }^{1}$. Once in the atmosphere, elemental mercury can float for over a year while oxidized mercury compounds could drift several days before precipitating to the earth (soil or water). Mercury in water can be converted by microorganisms to methylmercury, a highly toxic form, which may bio-accumulate in the food chain. With consumption of contaminated fish, humans are exposed to the mercury compounds. Research indicates that mercury compounds cause ecological and human health impacts.

Based on the ICR (Information Collection Request) from U.S. EPA (Environmental Protection Agency), coal-combustion power plants emitted around 48 tons of mercury in 1999, which was estimated to be one third of the total nationwide mercury emissions from human

\footnotetext{
* Author to whom correspondence should be addressed, Tel: 1-906-487-2600, Email: jhwang@mtu.edu
} 
activities $^{2}$. C.O. Bauer believed the estimate was $39.8 \%$ based on EPA's 1999 NEI (National Emission Inventory) ${ }^{3}$. As a matter of fact, coal-fueled electric utilities have become the largest anthropogenic source of atmospheric mercury in the United States.

EPA is developing a MACT (maximum achievable control technology) regulation to limit mercury emissions from power plants. The final MACT standard will be issued by December, 2004 and compliance is to be required by December 2007. In addition to EPA's MACT process, several multi-pollutant legislative proposals have been introduced in the $108^{\text {th }}$ Congress, including the Clear Skies Act, which would cap mercury emissions at 26 tons in 2010 and 15 tons in 2018 down from 1999 baseline level (48 tons) ${ }^{4}$.

The three technologies being evaluated recently for flue gas mercury control are activated carbon injection, FGD (flue gas desulfurization) spray dryers and wet scrubbers (wet FGD). Among them carbon injection technology is the closest to commercialization. Its average mercury removal efficiency is around $80-98 \%^{5}$. But the high cost (several billions of dollars as estimated in EPA's report to Congress) hinders its application in coal-fueled electric utilities. Finding a cost-effective sorbent with high mercury capture ability has generated great interest.

Unburned carbon must be extracted from fly ash in the fly ash recycling and cleaning processes before fly ash can be used in the cement industry ${ }^{6}$. To be used as cement additive, fly ash should not contain over 6\% carbon due to ASTM C618 specification (American Society for Testing and Materials). Under specific conditions, the market also forces carbon content in fly ash to be no more than $2 \%$ for concrete industry ${ }^{7,8,9}$. Meanwhile with the low NOx burners being employed in power plants to meet Clean Air Act Amendments in 1990s, the current carbon content in fly ash increased to as much as $20 \%$. Unburned carbon content is required to be reduced in fly ash to meet cement industry demands. In 2002, over 76.5 million tons of fly ash was produced from coal-fired power plants. The cement, concrete and grout industry utilized 14.5 million short tons of the available fly ash, amounting to $19 \%$ of total ${ }^{10}$. In 1991 , this ratio was $9 \%$ of the total amount of 51 million tons of fly ash ${ }^{11,12}$. Thus, a larger supply of unburned carbon separated from fly ash will be available in the future.

Based on the data from the American Coal Ash Association, the typical 2003 price for “concrete quality fly ash" was $\$ 20-45 /$ ton, which is $\$ 0.01$ to $\$ 0.0225 /$ lb. The prices for other usages of fly ash are much lower. The average price of activated carbon is over $\$ 0.5 / \mathrm{lb}$, showing that unburned carbon can beat activated carbon on price.

Unburned carbon possesses the property to capture mercury during the combustion process. Due to the short residence time in boilers, unburned carbon from fly ash may not reach its adsorption equilibrium and may still possess mercury capturing properties. Previous research ${ }^{13}$ has proven the $\mathrm{Hg}$ adsorption capacity of unburned carbon at low temperature $\left(20^{\circ} \mathrm{C}\right.$ $\left.\& 40^{\circ} \mathrm{C}\right)$. In this study, simulated flue gas temperature $\left(150^{\circ} \mathrm{C}\right)$ was used to investigate the $\mathrm{Hg}$ adsorption properties of carbon from various sources. 


\section{EXPERIMENTAL DESIGN}

In this study, two unburned carbon samples and one activated carbon sample were tested. AEP unburned carbon and Pepco unburned carbon were obtained from AEP (American Electric Power) fly ash, and Pepco (Potomac Electric Power) fly ash respectively. Both unburned carbon samples were extracted from class $\mathrm{F}$ fly ash using the froth flotation method under the same experimental conditions ${ }^{14,15,16}$. Activated carbon, F400, was obtained from Calgon Carbon Corporation, Pittsburgh, PA, USA. F400 is one of the most studied and widely used activated carbon products in vapor phase applications ${ }^{17}$.

Figure 1 illustrates the schematic diagram of the mercury vapor adsorption apparatus. $\mathrm{Hg}$ source was a $0.5 \mathrm{~cm}$ long mercury permeation tube (VICI Metronics. Inc., CA). The tube was placed at the bottom of a U-shaped glass tube and covered with glass beads to maintain uniform mercury vapor. A temperature-adjustable water bath maintained a required stable temperature. The carried gas was P.P. grade nitrogen gas. The concentrated mercury vapor was diluted with a bypass line of nitrogen gas before being introduced into the carbon reactor, which was a $1 \mathrm{~cm}$ I.D. (inside diameter), $22 \mathrm{~cm}$ long glass column. The mixture of the carbon sample and short glass fiber was placed in the middle of the column. Table 1 lists the related parameters. The carbon bed temperature was regulated by a tube furnace. Tygon tubing from Saint-Gobain Performance Plastics was selected for the connecting materials.

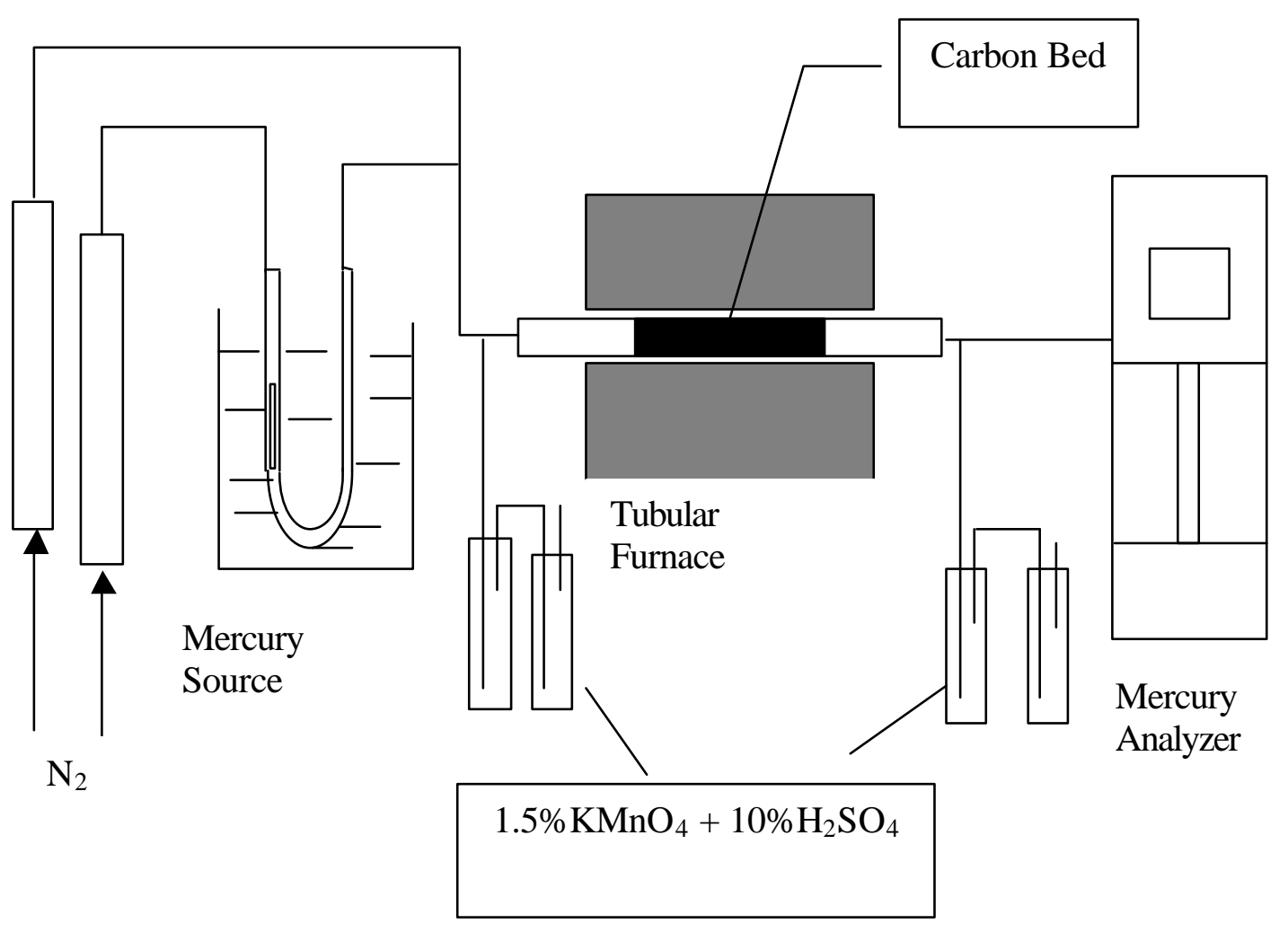

Figure1. Schematic Diagram of Mercury Vapor Adsorption Apparatus 
Table1. Parameters in Carbon Reactor

\begin{tabular}{|c|c|}
\hline Carbon bed inside diameter & $1 \mathrm{~cm}$ \\
\hline Carbon loading & $1.5 \mathrm{~g}$ \\
\hline Mercury source temperature & $45^{\circ} \mathrm{C}$ \\
\hline Carbon bed temperature & $150{ }^{\circ} \mathrm{C}$ \\
\hline Flow rate of carrier gas $\left(\mathrm{N}_{2}\right)$ & $50 \mathrm{ml} / \mathrm{min}$ \\
\hline Pressure of carrier gas & $20 \mathrm{psi}(1.36 \mathrm{~atm})$ \\
\hline
\end{tabular}

Mercury vapor was colleted using the one-liter Tedlar sampling bag at the site upstream and downstream of the carbon bed respectively. The collection time of the sample was set to seven minutes. Effluent mercury was recorded every 20 minutes in the first hour and every hour afterwards. Mercury vapor concentration was determined by a gold film mercury vapor analyzer (JEROME 431-X, Arizona Instrument Corp) ${ }^{18}$.

Exhaust vapor was introduced to the impinger solution before being expelled into the air. The impinger solutions were prepared daily by adding $1.5 \%$ potassium permanganate in $10 \%$ sulfuric acid ${ }^{19}$. The blank test was performed before each new adsorption experiment and lasted for 8 hours. After each test, the entire system was purged with pure nitrogen gas to expel $\mathrm{Hg}$ residues and this process lasted for 6-8 hours.

Calculation Method:

Total mercury adsorption was calculated using following integration equation:

$$
q^{\prime}=\int_{0}^{Q_{t}}\left(C_{0}-C_{t}\right)^{*} d Q_{t}
$$

where q' is total amount of adsorbed mercury, $\mathrm{C}_{0}$ and $\mathrm{C}_{\mathrm{t}}$ are influent and effluent $\mathrm{Hg}$ concentrations at time $t$, and $\mathrm{Q}_{t}$ is gas volume flowing into carbon bed at time $t$.

The quantity of mercury adsorption per unit carbon was calculated by following equation:

$$
q=\frac{\int_{0}^{Q_{t}}\left(C_{0}-C_{t}\right) * d Q_{t}}{m}
$$

where $\mathrm{q}$ is total captured mercury, and $\mathrm{m}$ is the mass of carbon sample.

\section{RESULTS \& DISCUSSION}

Mercury concentration in flue gas ranges from around $1 \mathrm{ppbv}$ to over several hundred $\mathrm{ppbv}^{20,21}$. For bituminous coal, this range is between $0.01 \mathrm{ppmv}$ and $3.3 \mathrm{ppmv}^{22}$. The nominal flue gas temperature is $149^{\circ} \mathrm{C}\left(300^{\circ} \mathrm{F}\right)$. In this study, carbon bed was set at $150^{\circ} \mathrm{C}$, and mercury influent concentration was adjusted at around $0.05 \mathrm{mg} / \mathrm{m}^{3}$. 


\section{Effect of Carbon Sources:}

The origin of carbon affects its adsorption capacity. Carbon from various sources shows entirely different performance. Figure 2 illustrates the adsorption curves of AEP unburned carbon, Pepco unburned carbon and F400 activated carbon at $150^{\circ} \mathrm{C}$ and with influent $\mathrm{Hg}$ of $0.05 \mathrm{mg} / \mathrm{m}^{3}$. F400 possesses much better adsorption behavior, it captured around twice the amount of mercury that AEP adsorbed within the same time frame of testing. During the entire sorption process, Pepco carbon did not show any positive adsorption ability. Actually, it emitted over $0.066 \mu \mathrm{gHg} / \mathrm{gCarbon}$, which is assumed to be the result of the fleeing of preloaded mercury from unburned carbon surface.

\section{Effect of Temperature:}

The influence of temperature on the adsorption capacity of the carbon samples was studied at one typical low temperature, $20^{\circ} \mathrm{C}$ and one typical high temperature, $150^{\circ} \mathrm{C}$, and with flowing $\mathrm{Hg}$ content as $0.05 \mathrm{mg} / \mathrm{m}^{3}$. As shown in Figure 3, with temperature increasing, adsorption capacity of two unburned carbon samples decreased dramatically. The capacity of AEP carbon dropped $65 \%$ with temperature increasing from $20^{\circ} \mathrm{C}$ to $150^{\circ} \mathrm{C}$. It adsorbed $2.6 \mu \mathrm{g}$ $\mathrm{Hg} / \mathrm{gCarbon}$ at $20^{\circ} \mathrm{C}$, and $0.9 \mu \mathrm{gHg} / \mathrm{gCarbon}$ at $150^{\circ} \mathrm{C}$. Pepco carbon captured $0.24 \mu \mathrm{g} \mathrm{Hg}$ per gram carbon at $20^{\circ} \mathrm{C}$, and it did not capture any mercury at $150^{\circ} \mathrm{C}$. High temperature caused a reduction in the adsorption capacity of the carbon samples, which is consistent with physical sorption theory.

\section{Effect of Influent Mercury Concentration:}

Gaseous $\mathrm{Hg}$ content in flowing vapor affected the adsorption behavior of carbon samples. Figure 4 presents the adsorption curves of the three carbon samples at a temperature of $150^{\circ} \mathrm{C}$ and for the concentrations of $0.05 \mathrm{mg} / \mathrm{m}^{3}$ and $0.1 \mathrm{mg} / \mathrm{m}^{3}$. All carbon samples, including unburned carbon and activated carbon, indicate faster capturing rates at high inlet $\mathrm{Hg}$ concentration. Especially, the Pepco carbon, which adsorption capacity increased from negative to over $0.09 \mu \mathrm{gHg} / \mathrm{gCarbon}$ with increasing of $\mathrm{Hg}$ concentration from $0.05 \mathrm{mg} / \mathrm{m}^{3}$ to $0.1 \mathrm{mg} / \mathrm{m}^{3}$. With high content in flowing vapor, vapor-phase $\mathrm{Hg}$ atoms have more chances to hit on carbon surface and be attached, which results in better adsorption behavior.

\section{Effect of Preloaded Mercury:}

Unburned carbon contains preloaded mercury due to its origin from fly ash. The emission of preloaded $\mathrm{Hg}$ from unburned carbons at the temperature of $150^{\circ} \mathrm{C}$ with $\mathrm{Hg}$-free vapor passing through was examined and the influence of this emission on the adsorption behavior of carbons was also studied. Figure 5 displays desorption curves of Pepco and AEP carbons at $150^{\circ} \mathrm{C}$. AEP carbon was recorded to emit around $0.019 \mu \mathrm{gHg} / \mathrm{gCarbon}$ in around 30 minutes testing, and the total amount of $\mathrm{Hg}$ preloaded on the AEP unburned carbon should be higher, since it still can emit $0.007 \mathrm{mgHg} / \mathrm{m}^{3}$ at the end of the experiment. The Pepco carbon emitted about 0.14 $\mu \mathrm{gHg} / \mathrm{gCarbon}$ in around 90 minutes of testing, and the preloaded $\mathrm{Hg}$ it contained should be higher than this since it did not emit all the $\mathrm{Hg}$ it held till the end of testing.

The phenomenon that the preloaded mercury could emit from the carbon surface under experimental conditions would affect mercury adsorption performance of the unburned carbon. In this study, the adsorption capacities of unburned carbons were modified respectively by adding the amount of $\mathrm{Hg}$ captured in the adsorption test and the amount of $\mathrm{Hg}$ emitted in the 
desorption tests, and the results are shown in Figure 6 with those without modification As shown in Figure 6, unburned carbons with modification indicated better adsorption behaviors, especially the Pepco carbon, with modification its adsorption capacity changed from negative to close to AEP carbon. The actual adsorption performance shows poor performance than the modified one, which demonstrates the previous assumption that the fleeing of the preloaded $\mathrm{Hg}$ from carbon surface reduced the further $\mathrm{Hg}$ capturing ability of carbon sample. Meanwhile, it supplied the explanation why Pepco carbon showed negative adsorption capacity during testing.

To diminish the influence of preloaded mercury emission from carbon surface at a temperature around $150^{\circ} \mathrm{C}$, a desorption process could be conducted before the adsorption test. Previous researches demonstrated that AEP carbon increased its adsorption capacity at a low temperature $\left(20^{\circ} \mathrm{C}\right.$ and $\left.40^{\circ} \mathrm{C}\right)$ after a desorption at $400^{\circ} \mathrm{C}$ with the presence of oxygen. The desorption test for unburned carbon at a high temperature (over $400^{\circ} \mathrm{C}$ ) will be conducted in the future.

\section{CONCLUSION}

The adsorption capacity of carbon samples was source-dependent. At the temperature of $150^{\circ} \mathrm{C}$ and the influent $\mathrm{Hg}$ concentration of $0.05 \mathrm{mg} / \mathrm{m}^{3}$, commercial grade activated carbon demonstrated the best adsorption ability among the three tested carbons. AEP unburned carbon was better than Pepco unburned carbon. Pepco unburned carbon had a range of negative to very little mercury adsorption capability.

The adsorption capacities of the three tested carbons were temperature sensitive. The mercury capturing capacity of all carbon samples decreased when carbon bed temperature increased. This is consistent with the physisorption theory.

The adsorption rates of all three carbon samples increased with influent $\mathrm{Hg}$ content. When gaseous $\mathrm{Hg}$ concentration increased, Pepco unburned carbon changed its capacity from negative to positive. AEP unburned carbon indicated larger increasing rate than F400 activated carbon when the gaseous $\mathrm{Hg}$ content shifted from low to high.

The specific property of unburned carbon caused its adsorption process a combination of adsorbing mercury from flowing vapor and desorbing the preloaded $\mathrm{Hg}$ to the flowing vapor. The emission of preloaded $\mathrm{Hg}$ weakened the further mercury capturing ability of the carbon. For improvement, a desorption pretreatment before adsorption process for unburned carbon is required, especially for Pepco carbon. The desorption test at the temperature of $400^{\circ} \mathrm{C}$ with the presence of oxygen was performed for AEP carbon, which enhanced its adsorption capacity at a low temperature $\left(20^{\circ} \mathrm{C} \& 40^{\circ} \mathrm{C}\right)$. 


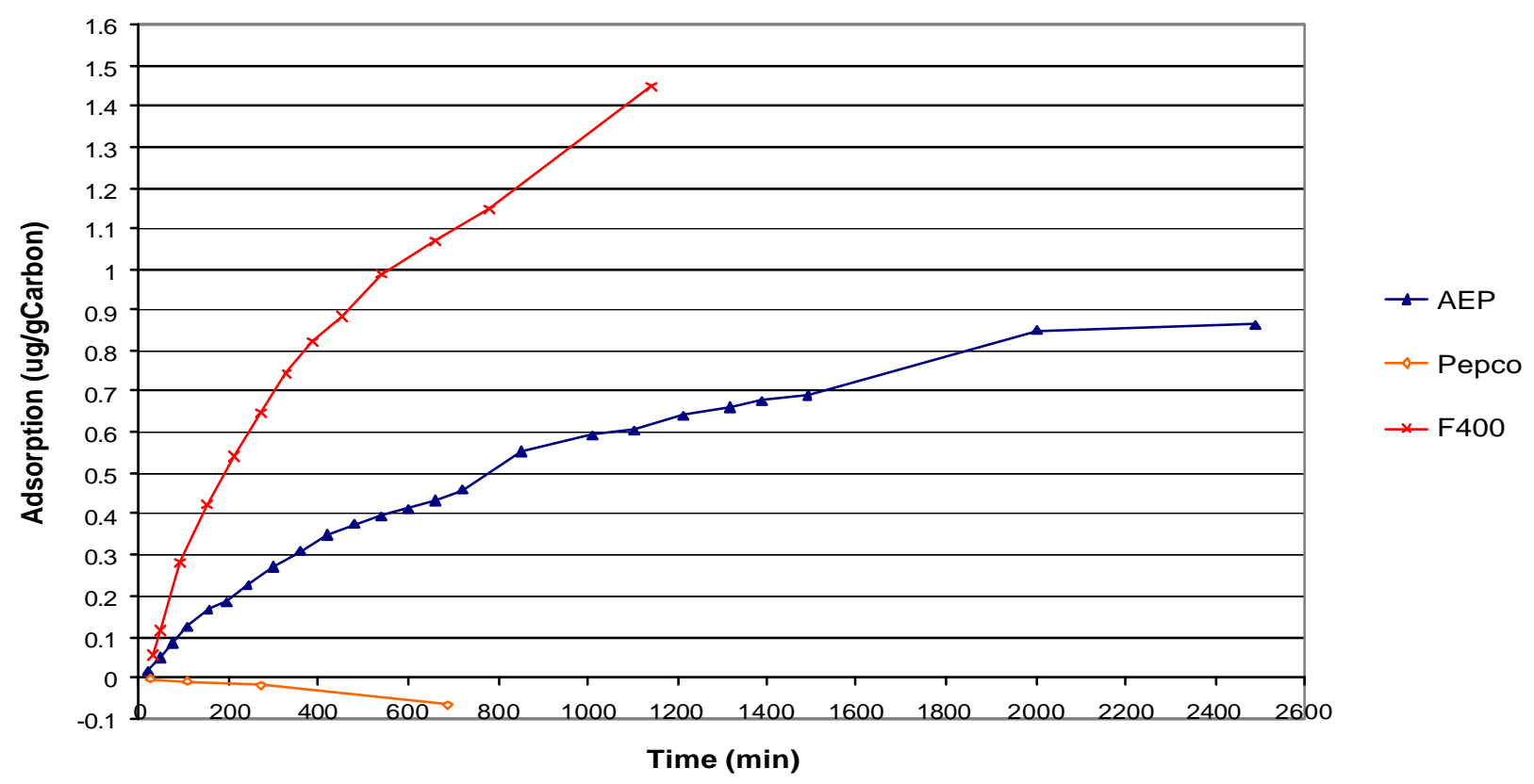

Fig. $2 \mathrm{Hg}$ Adsorption Capacities of 3 Different Carbons at $150^{\circ} \mathrm{C}, 0.05 \mathrm{mg} / \mathrm{m}^{3}$

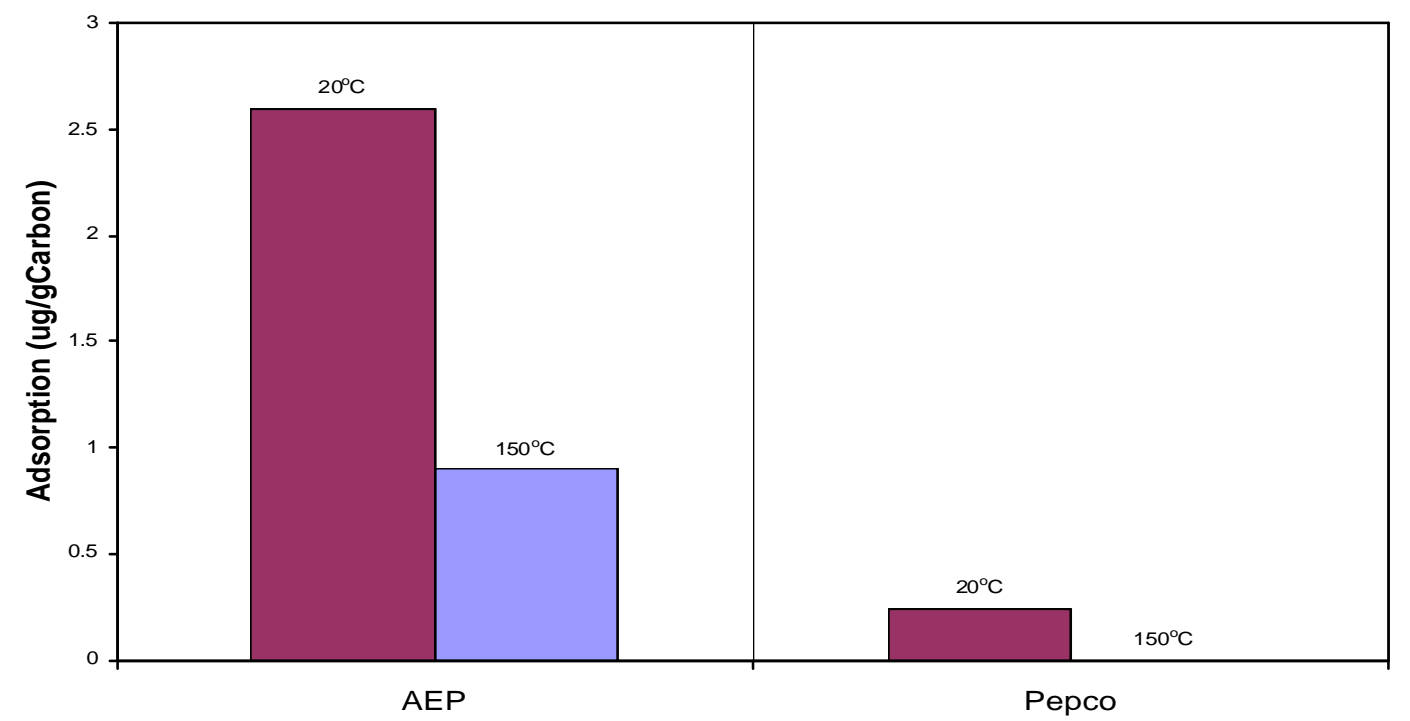

Fig. 3 Influence of Temperature on adsorption for Two Unburned Carbons 


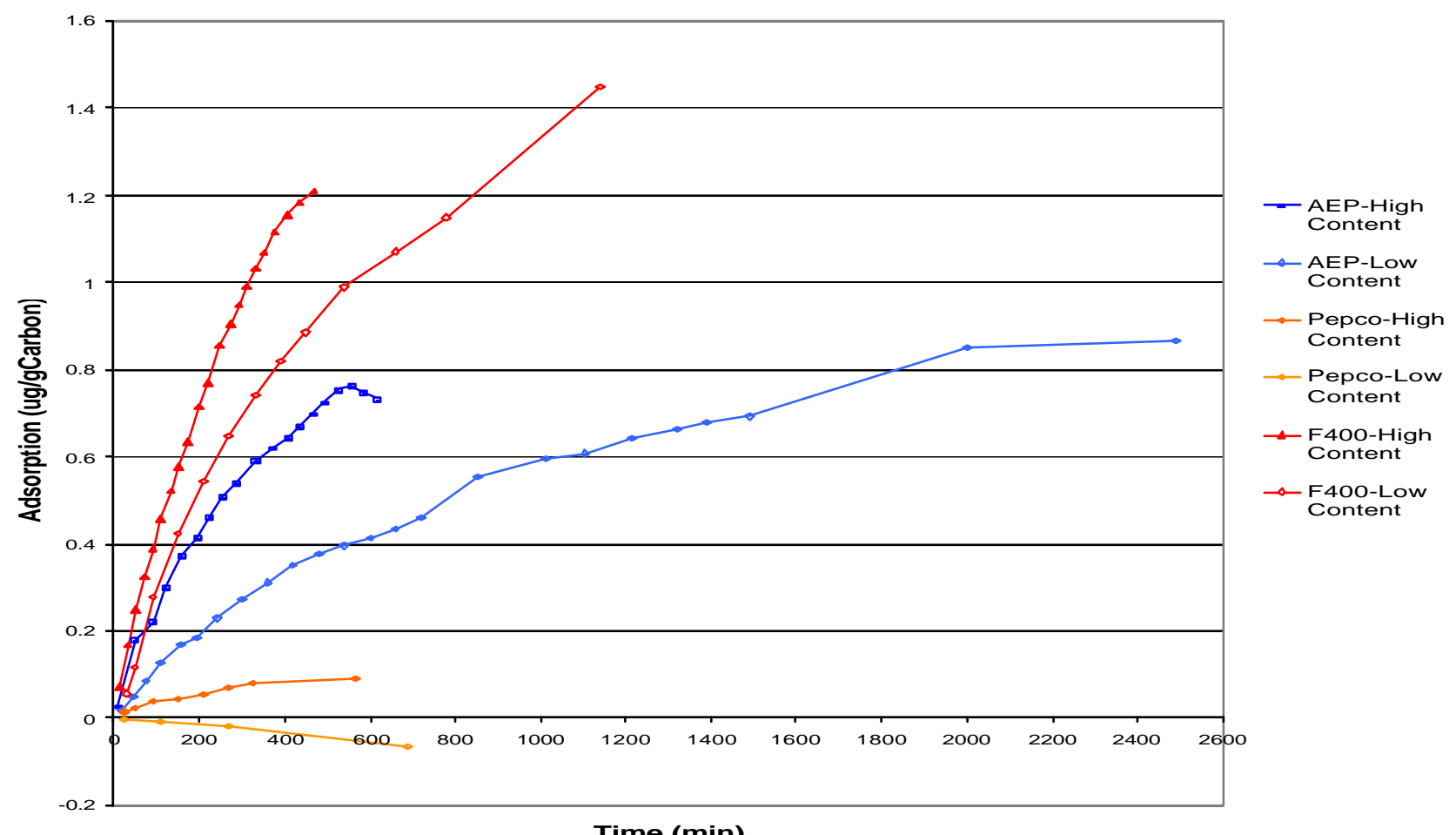

Fig. 4 Effect of Hg Concentration on the Adsorption for Different Carbons at $158 \mathrm{C}$

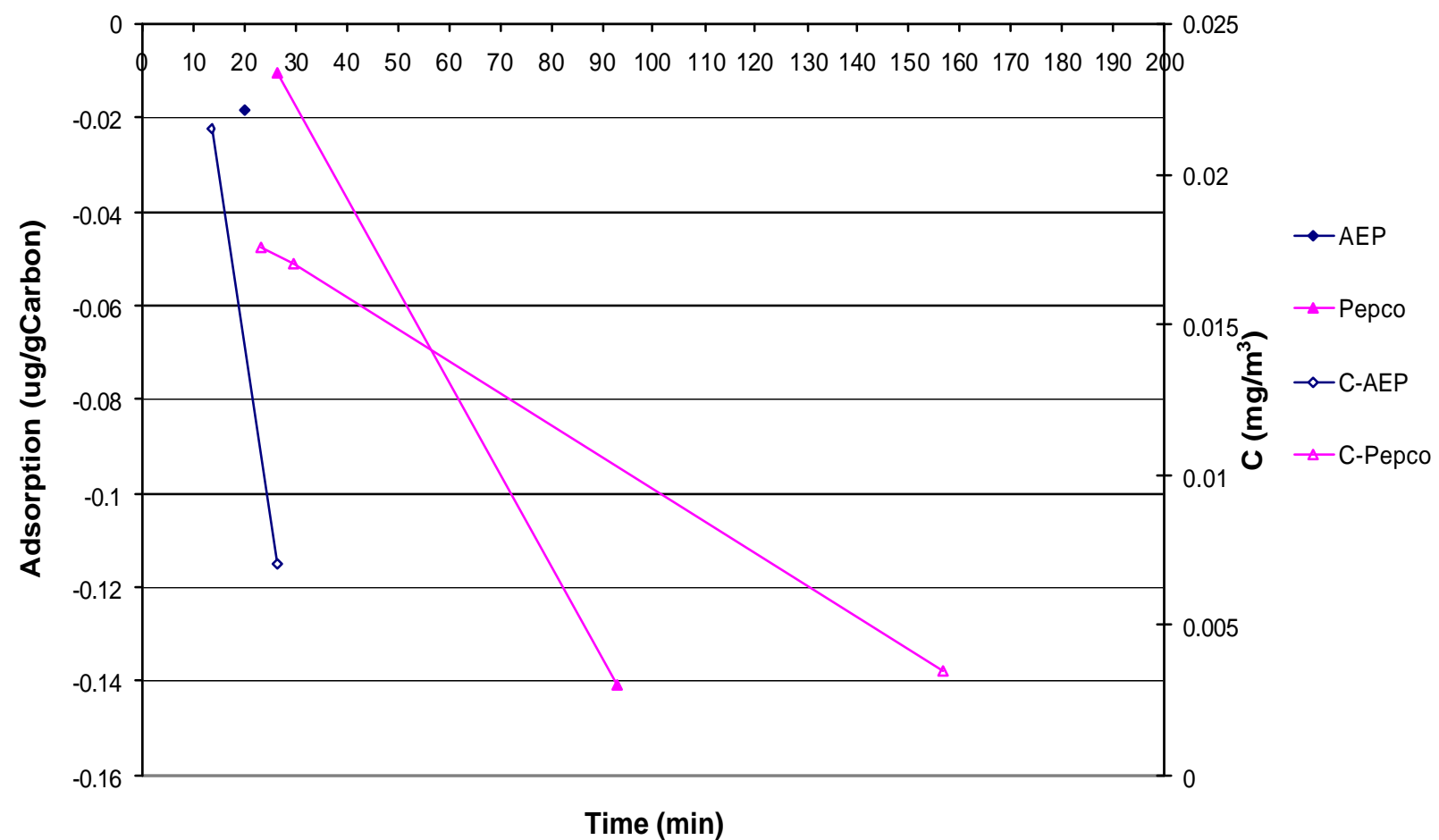

Fig. $5 \mathrm{Hg}$ Contained in Unburned Carbons 


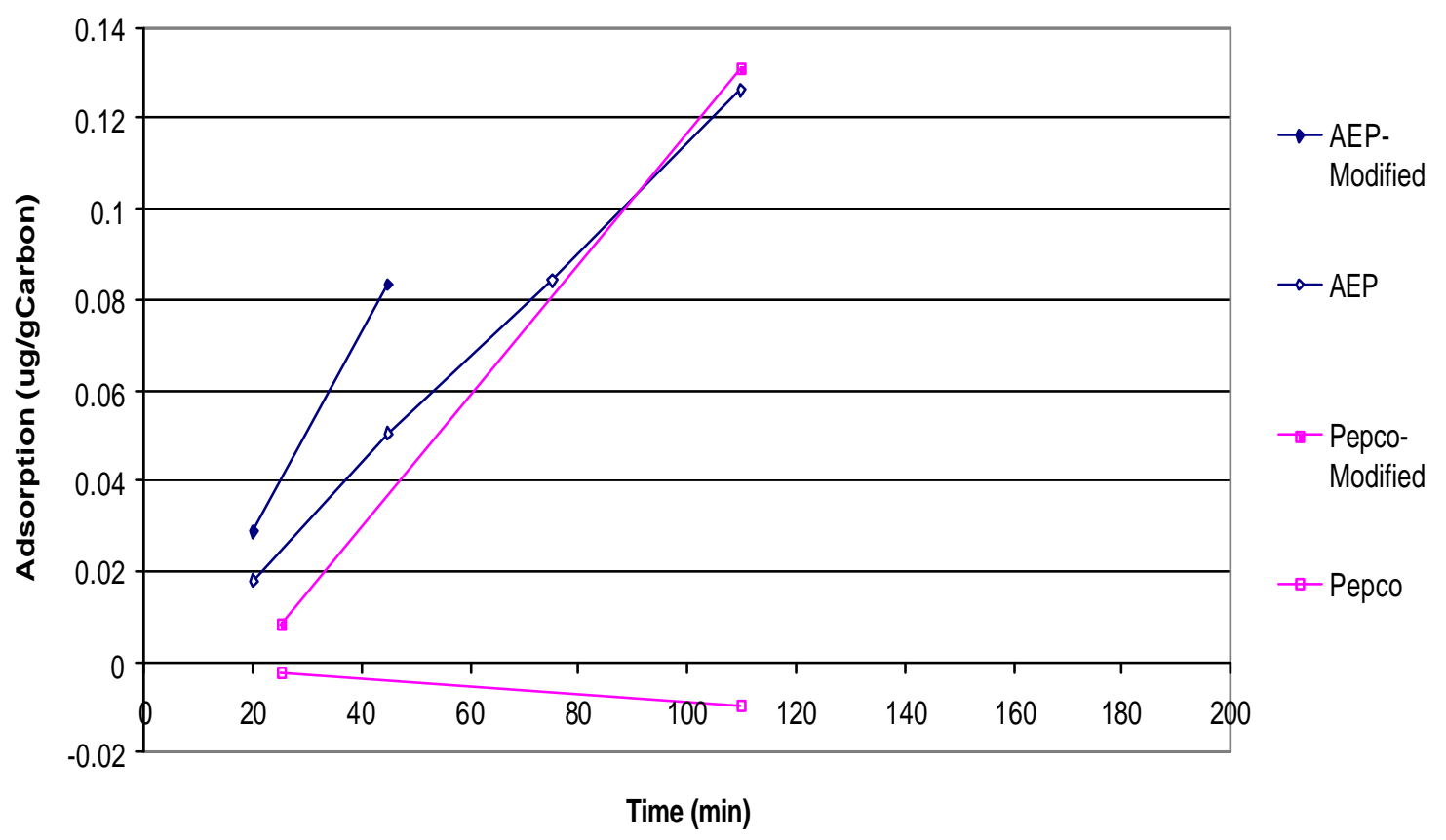

Fig. 6 Comparison Hg Adsorption Capacities Between Unburned Carbons With or Without Modificatoin at $150^{\circ} \mathrm{C}, 0.055 \mathrm{mg} / \mathrm{m}^{3}$

\section{REFERENCE:}

${ }^{1}$ U.S. EPA Mercury Study Report to Congress, EPA-452/R-97-003, December 1997

2 Thomas J. Feeley,III, James Murphy, Jeffrey Hoffmann, and Scott A. Renninger, A Review of DOE/NETL's Mercury Control Technology R\&D Program for Coal-Fired Power Plants, April 2003

${ }^{3}$ Carl O. Bauer, DOE-NETL's Mercury R\&D Program, 2003

${ }^{4} \mathrm{http}: / / \mathrm{www}$. epa.gov/air/mercuryrule/

${ }^{5}$ Mercury Control Options for Coal-Fired Power Plants, Clean Air Network Fact Sheet, August 1999

${ }^{6}$ J.Y. Hwang, "Unburned Carbon from Fly Ash, A Hidden Treasure," $3^{\text {rd }}$ Annual Conference on Unburned Carbon on Utility Fly Ash, U.S. Department of Energy, May 1997, Pittsburgh, Pennsylvania

${ }^{7}$ Use of High-Carbon Fly Ash in Cement Manufacture

8 J.Y. Hwang, "Powder Technology in Concrete," Powder Metallurgy, V. 40, No. 3, p. 160

${ }^{9}$ X.M. Song, J.Y. Hwang, and X. Liu, "Utilization of Beneficiated Low NO $\mathrm{X}$ Fly Ash in

Concrete and Concrete Block," Proceedings: $12^{\text {th }}$ International Symposium on Coal Combustion By-Product (CCB) Management and Use, Vol. 1, EPRI TR-107055-V1, January 1997, pp.30-130-16

${ }^{10} 2002$ Coal Combustion Product Production and Use Survey, American Coal Ash Association

${ }^{11}$ American Coal Ash Association 
${ }^{12}$ R. S. Kramer, J. Y. Hwang, X. Huang, and T. Hozeska, "Characterization of Recyclable Components in Fly Ash to Produce Marketable Products," 1994 TMS Annual Meeting \& Exhibition, San Francisco, California, February 27-March 3, 1994

${ }^{13}$ Z.Li, X.Sun, J.Luo, J.Y.Hwang, J.C.Crittenden, "Unburned Carbon from Fly Ash for Mercury Adsorption: II. Adsorption Isotherms and Mechanisms", Journal of Minerals \& Materials Characterization \& Engineering, Vol1. No.2, p79-96

${ }^{14}$ J.Y.Hwang, "Wet Process for Fly Ash Beneficiation," U.S. Patent 5,047,145 (1991).

15 J.Y.Hwang, X.Sun, Z.Li, "Unburned Carbon from Fly Ash for Mercury Adsorption: I. Separation and Characterization of Unburned Carbon", Journal of Minerals \& Materials Characterization \& Engineering, Vol1. No.1, p39-60

${ }^{16}$ J.Y. Hwang, X. Huang, J. Gillis, A. Hein, D. Popko, R. Tieder, and M. McKimpson, "Separation and Utilization Technologies of Low NOx Ash," Proceedings: $13^{\text {th }}$ International Symposium on Use and Management of Coal Combustion By-Products, Vol. 1, pp. 19-1-19-22.

${ }^{17}$ Product brochure, Calgon Carbon Corporation

18 JEROME 431-X Mercury Vapor Analyzer Manue

${ }^{19}$ Shendrikar, A.D.; Damle, A.; Gutknect, W.F. Collection Efficiency Evaluation of Mercury Trapping Media for the SASS Train Impinger System, U.S. Environmental Protection Agency. U.S. Government Printing Office: Washing, DC, 1984, EPA-600/7-84-089

${ }^{20}$ V.K. Mathur and Z.Y. Chen, Mercury Oxidization in Non-Thermal Barrier Discharge System

${ }^{21}$ U.S. EPA Mercury Study Report to Congress, Volume VIII: An Evaluation of Mercury Control Technologies and Cost, December 1997

${ }^{22}$ Livengood,C.D.; Huang,H.S.; Wu,J.M. "Proceedings of the $87^{\text {th }}$ Annual Meeting of the Air and Waste Management Association, 1994, reprint, p14 